\title{
Emerging Trends on Optimization and Control under Uncertainty in Transportation and Construction
}

\author{
Honglei Xu $\mathbb{D}^{1},{ }^{1}$ Gerhard-Wilhelm Weber, ${ }^{2,3}$ and Shenping Xiao $\mathbb{D}^{4}$ \\ ${ }^{1}$ Curtin University, Perth, Australia \\ ${ }^{2}$ Faculty of Engineering Management, Poznan University of Technology, Poznan, Poland \\ ${ }^{3}$ Institute of Applied Mathematics, METU, Ankara, Turkey \\ ${ }^{4}$ Hunan University of Technology, Zhuzhou, China
}

Correspondence should be addressed to Honglei Xu; h.xu@curtin.edu.au

Received 26 March 2019; Accepted 26 March 2019; Published 18 April 2019

Copyright (C) 2019 Honglei Xu et al. This is an open access article distributed under the Creative Commons Attribution License, which permits unrestricted use, distribution, and reproduction in any medium, provided the original work is properly cited.

In the real world, many problems are characterized by the necessity of making decisions with incomplete information and uncertainty. In such settings, many existing optimization and control results need to be redeveloped to cope with these uncertain effects and a variety of interesting challenges should be tackled at the same time. In fact, those emerging problems are a key source of new research and application. Innovative approaches for new computational and theoretical results of stochastic (robust) optimization and optimal control are critical to provide best decisions in the perturbative environments.

On the other hand, in the area of application such as transportation and construction, the uncertainty effect has received strong attention widely and is regarded as an important reason to decrease the system efficiency. To control and maximize the efficiency, various optimization and control problems under uncertainty are expected to be formulated and solved appropriately using advanced analytical or numerical methods.

This special issue collects seventeen high-quality papers related to methodologies of dealing with uncertainty in optimization and control and the linkages between theoretical methodology and emerging applications. It will be valuable for both academics and industry practitioners.

The paper entitled "Experimental and Numerical Analysis and Prediction of Ground Vibrations Due to Heavy Haul Railway Viaduct" by J. Hu et al. analyzes the ground vibration around Shenshan Village in section of Shuo-Huang railway line and proposes the concept of energy index. Test results validate the accuracy of the mathematical and predictive models.

The paper entitled "A Supply Chain-Logistics SuperNetwork Equilibrium Model for Urban Logistics Facility Network Optimization" by Y. Su et al. establishes a logistics super network equilibrium via the variational inequality theory. It derives the equilibrium condition of the network and provides economic explanation. It also indicates that a scientific planning scheme for storage facilities is important for the relation of commodity supply and demand.

The paper entitled "Optimization and Control on High Frequency Resonance of Train-Network Coupling Systems" by J. Zhang et al. analyzes new harmonic characteristics of mixed running of alternating current (AC) and direct current (DC) trains in electrified railway to solve high frequency resonance problems in train network coupling systems.

The paper entitled "A Hybrid Approach for Project Crashing Optimization Strategy with Risk Consideration: A Case Study for an EPC Project" by C. Ou-Yang and W.-L. Chen provides an evaluation strategy for schedulerelated variations and time-cost analysis for an engineeringprocurement-construction projects. It proposes a hybrid method for the time-cost optimization strategy evaluation of and Monte Carlo simulation for contingency plans and optimal assess strategies for project execution under time and cost constraints

The paper entitled "Modeling and Speed Control of the Underwater Wheeled Vehicle Flexible Towing System" by G. Liu et al. studies the dynamic characteristics of the towing 
system and proposes a master-slave synchronization control technique. Then, it proposes fast terminal sliding mode control to design a speed controller.

The paper entitled "Influence Zone Division and Risk Assessment of Underwater Tunnel Adjacent Constructions" by Z. Zhou et al. applies the Hoek-Brown nonlinear failure criterion of rock mass to study the stress state of rock mass around the underwater tunnel adjacent constructions. It proposes the influence zone division method of underwater tunnel adjacent constructions and applies it to analyze engineering practices.

The paper entitled "Fuzzy Iterative Sliding Mode Control Applied for Path Following of an Autonomous Underwater Vehicle with Large Inertia” by G. Wang et al. develops a fuzzy iterative sliding mode control scheme for special autonomous underwater vehicles on three-dimensional path following. The control algorithm can optimize the control parameters online to enhance the system adaptability.

The paper entitled "A Two-Stage Stochastic Model for Maintenance and Rehabilitation Planning of Pavements" by M. Ameri et al. establishes a two-stage stochastic model to address uncertainty in budgeting and develops an executive model for network level maintenance and rehabilitation planning. Even though the two-stage stochastic model may increase the total cost compared to the deterministic, it will be more compatible for budget variation.

The paper entitled "Control Strategy for the Energy Optimization of Hybrid Regenerative Braking Energy Utilization System Used in Electric Locomotive" by J. Yan et al. develops an energy optimization scheme by combining energy storage control and energy optimization. A tracking control of the instantaneous power is designed for distributing the regenerative braking energy.

The paper entitled "Improved Simulated Annealing Based Network Model for E-Recycling Reverse Logistics Decisions under Uncertainty" by L. Wang et al. investigates a novel approach to design the e-recycling reverse logistics network under uncertainty. The approach consists of a matrix-based simulation model and a simulated annealing algorithm to generate. The paper conducts network static analysis and proposed static network generation process and index design.

The paper entitled "Optimizational Mathematical Modeling Methods of DC Traction Power Supply System for Urban Mass Transit" by J. Shang et al. proposes an optimization mathematical modeling method of DC traction power supply systems and gets the node admittance network equation of DC traction power supply system based on the self-adaptive real-time dynamics of node arrays and input parameter documents.

The paper entitled "Models and Methods for TwoEchelon Location Routing Problem with Time Constraints in City Logistics" by P. Yang and L. Zeng studies the twoechelon location routing problem with time constraints in city logistics system. It develops a mathematic model to optimize the locations and a metaheuristic algorithm to solve it.

The paper entitled "Robust Impulsive Stabilization of Uncertain Nonlinear Singular Systems with Application to Transportation Systems" by S. Fang develops a new impulsive control technique to make a singular system robustly asymptotically stable. It derives sufficient stability conditions in the form of algebra matrix inequalities to solve them numerically.

The paper entitled "Supply Chain Cost Prediction for Prefabricated Building Construction under Uncertainty" by S. Wang et al. predicts a supply chain cost for prefabricated building construction under an uncertain situation using an activity-based costing method. It also establishes a computational model to estimate the total cost of the prefabricated supply chain.

The paper entitled "Determining Equivalent Administrative Charges for Defined Contribution Pension Plans under CEV Model" by $\mathrm{H}$. Chen studies the determination of the equivalent administrative charges on balance and on flow and applies the maximum principle and the stochastic control theory to obtain the explicit solutions of the equivalent equation about the charges.

The paper entitled "Stationary Gas Networks with Compressor Control and Random Loads: Optimization with Probabilistic Constraints" by M. Gugat and M. Schuster investigates a stationary model of gas flow using simplified isothermal Euler equations in non-cycled pipeline networks. The support of compressor stations will counteract the pressure loss of the pipes. Optimal solutions exist for some optimization problems with probabilistic constraints.

Finally, the paper entitled "Joint Decision on Ordering and Pricing of Cruise Tourism Supply Chain with Competing Newsboy-Type Retailers" by M. Shi and B. Liu studies a cruise tourism supply chain system composed of one supplier and two newsboy-type retailers. It derives optimal decisions in a decentralized system from a game theoretical perspective and obtains the optimal ordering and pricing strategies of both retailers and the optimal wholesale prices of the supplier with the limited number of cruise tickets.

We believe that the special issue will be very useful for experts and practitioners working in the broad engineering and academic communities.

\section{Conflicts of Interest}

The editors declare that they have no conflicts of interest regarding the publication of this special issue.

\section{Acknowledgments}

The editors would like thank all authors of the special issue for their valuable submitted papers and to all reviewers for their professional comments and feedback. We take the opportunity to thank all co-editors and particularly Professor Xinhua Jiang from Fuzhou University of Technology for his help and guidance. Finally, we are very grateful to the Editors and Publishers of prestigious Mathematical Problems in Engineering for the opportunity of preparing this special issue.

Honglei $\mathrm{Xu}$

Gerhard-Wilhelm Weber Shenping Xiao 


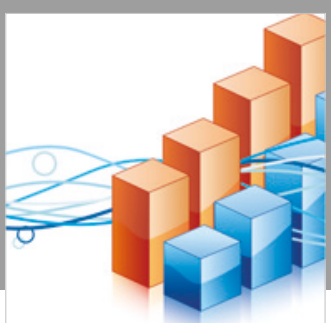

Advances in

Operations Research

\section{-n-m}
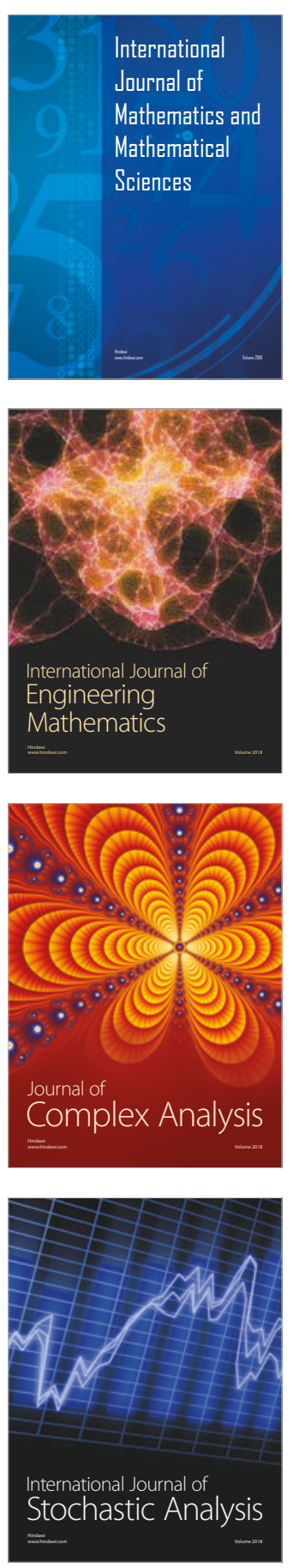
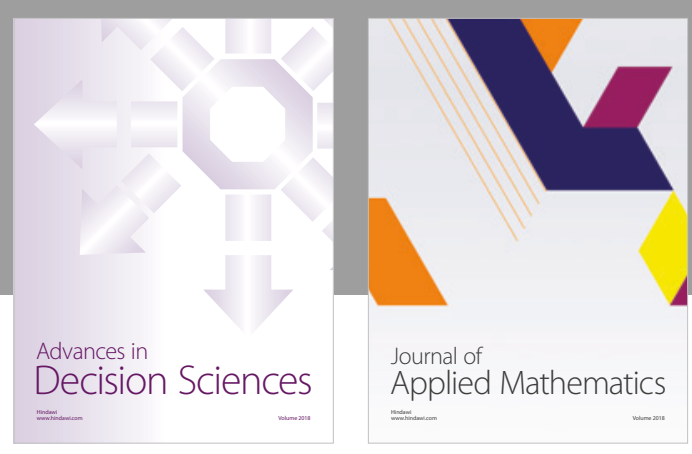

Journal of

Applied Mathematics
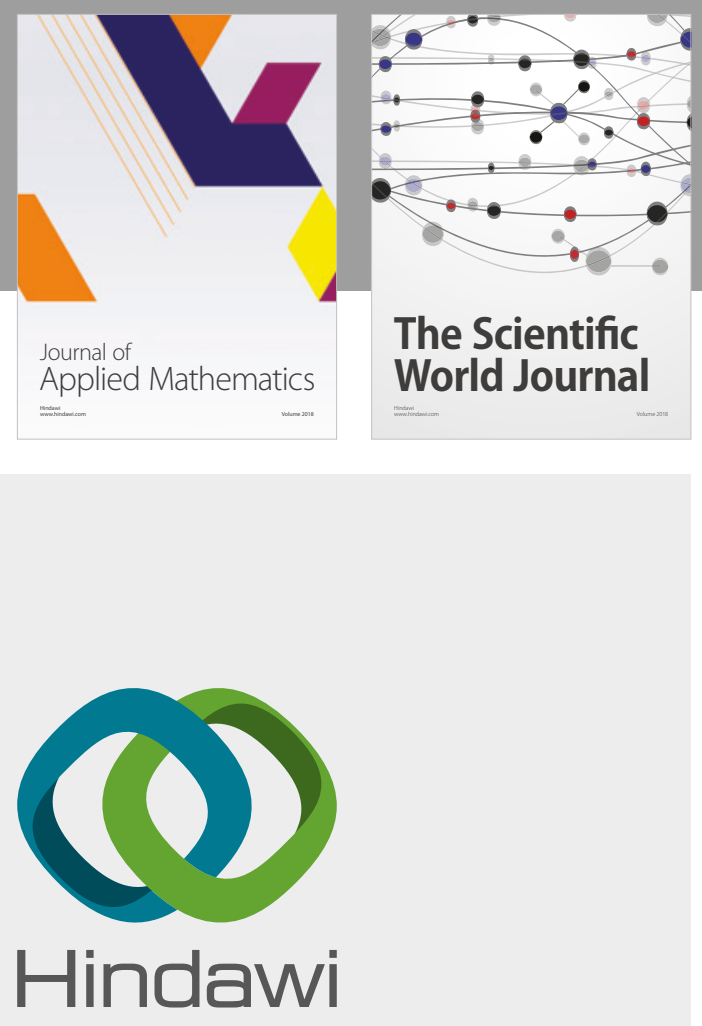

Submit your manuscripts at

www.hindawi.com

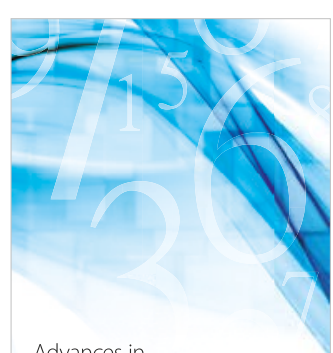

Advances in
Numerical Analysis
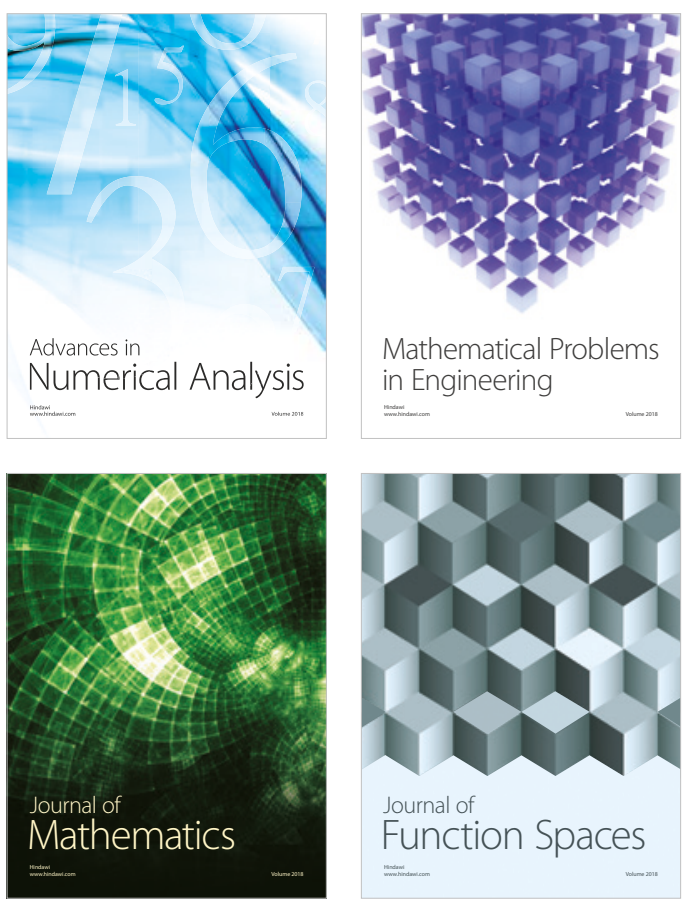

Mathematical Problems in Engineering

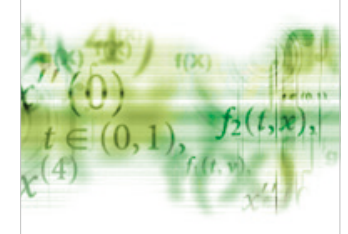

International Journal of

Differential Equations

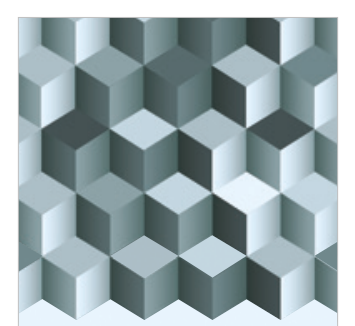

Journal of

Function Spaces

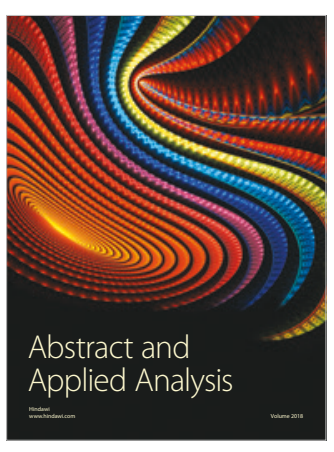

The Scientific

World Journal

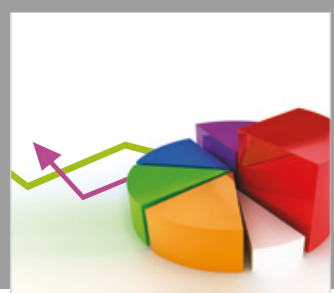

Journal of

Probability and Statistics
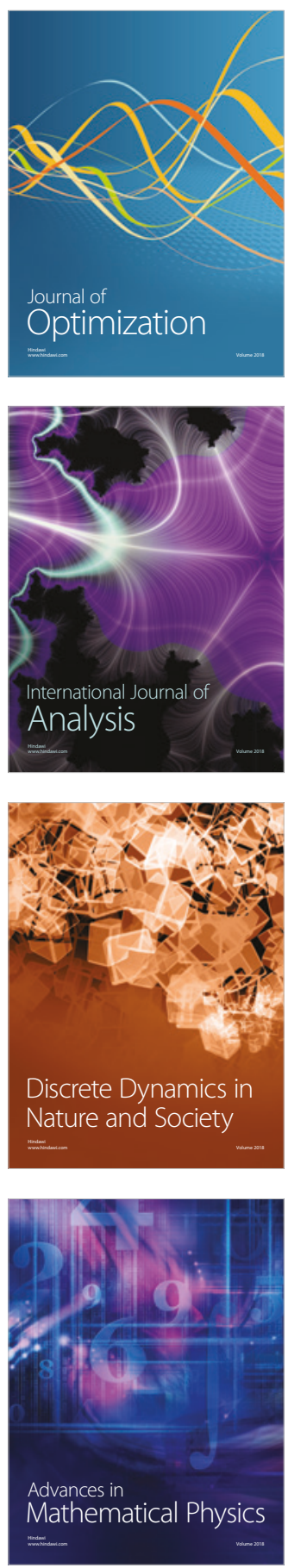